\title{
Ficus racemosa L. Leaf Extracts Lack Antibacterial activity and are Toxic in vitro
}

\author{
Lindiwe Mpala', Getmore Chikowe', Ian Edwin Cock ${ }^{1,2, *}$ \\ 'School of Environment and Science, Nathan Campus, Griffith University, 170 Kessels Rd, Nathan, Brisbane, Queensland, AUSTRALIA. \\ 2Environmental Futures Research Institute, Griffith University, 170 Kessels Rd, Nathan, Brisbane, Queensland, AUSTRALIA.
}

\begin{abstract}
Introduction: Closely related plant species often share similar secondary metabolites and bioactivities and are therefore good targets for bioactivity testing when one or more species within a genus are known to possess therapeutic properties. The genus Ficus has a long history of medicinal usage in many areas of the world. Many species are known to have therapeutic properties, several species of which have well established antibacterial bioactivities. Methods: The ability of $F$. racemosa leaf extracts to inhibit the growth of a panel of bacterial pathogens was investigated by disc diffusion assay. Toxicity was examined using the Artemia franciscana nauplii bioassay. Results: F. racemosa methanolic and aqueous extracts were completely ineffective at inhibiting the growth of gram-positive and gram-negative panels of bacteria. The extracts were nontoxic or of low toxicity following $24 \mathrm{~h}$ exposure. Conclusion: Despite the close taxonomic relationship with several bioactive Ficus spp. and its therapeutic uses in traditional medicine, F. racemosa leaf extracts were completely ineffective
\end{abstract}

bacterial growth inhibitors. However, these extracts may have other therapeutic properties and testing against protozoa, fungi, virus and tumour cells is required.

Key words: Myrtaceae, Rose gum, Antibacterial activity, Australian plant, Traditional medicine, Medicinal plants, Toxicity.

\section{Correspondence:}

Dr. Ian Edwin Cock

${ }^{1}$ School of Environment and Science, Nathan Campus, Griffith University, 170 Kessels Rd, Nathan, Brisbane, Queensland 4111, AUSTRALIA.

${ }^{2}$ Environmental Futures Research Institute, Griffith University, 170 Kessels Rd, Nathan, Brisbane, Queensland 4111, AUSTRALIA.

Phone no: +61 737357637

E-mail: i.cock@griffith.edu.au

DOI: $10.5530 /$ pc.2020.1.9

\section{INTRODUCTION}

The use of natural plant therapeutics is as old as human civilisation and in many regions of the world is still the primary modality of health care. Ayuverdic medicine in India for example is still commonly practiced, with approximately $85 \%$ of Indians using crude plant preparations for the treatment of various diseases and ailments. ${ }^{1}$ Even in Western civilisations, plants play an important role in medicine. At least $25 \%$ of pharmaceuticals prescribed worldwide are directly obtained from plants with many more drugs being semi-synthetic derivatives of natural plant precursors. ${ }^{2-4}$ Examples of medicinally important plant derived compounds include the anti-malarial drug quinine and its derivatives (from Cinchona spp.), the antitumour drugs vincristine and vinblastine (from Catharanthus roseus) along with the semi-synthetic analogue vindesine, the analgesics morphine and codeine (from Papaver somniferum), the anticholinogenic drug atropine derived from plants of the family Solinaceae (Atropa belladonna, Datura stramonium and Mandragora officinarum), the anticancer drug taxol (derived from Taxus brevifolia) and the cardiac glycoside digoxin (from Digitalis purpurea) ${ }^{5}$

Despite the potential of plants to provide us with useful pharmaceutical agents, the field is still relatively poorly studied. Only an estimated 5-10\% of the approximately 300,000-500,000 plant species worldwide have been screened for 1 or more bioactivities. ${ }^{5}$ With so many plant species yet to be tested, it is essential that plant selection processes narrow the field. The main selection criteria currently used is to select plants on the basis of ethnobotanical usage as traditional medicines. Another important selection method is to examine plants closely related to plants for which medicinal potential is well established. Many plant secondary metabolites are regarded as family, genus or species specific and investigation of species closely related to those used as traditional medicines may lead to natural therapeutic discovery. ${ }^{2}$

In recent years, the development of bacterial pathogens that are either extremely (XDR) or totally drug resistant (TDR) to common clinically used antibiotics ${ }^{6}$ has resulted in the need to develop new antibiotic chemotherapies. There are now limited therapeutic options for many diseases caused by bacterial pathogens and the situation is expected to worsen in the future as bacteria exchange resistance genes. Indeed, the development of alternative antibacterial treatment modalities has become crucial and is considered by the World Health Organisation (WHO) to be one of the most serious challenges facing medical science. ${ }^{7}$ For a number of reasons reviewed elsewhere, ${ }^{6}$ it is unlikely that the previous methods of antibiotic discovery/development will be as successful in the future and new treatment modalities are urgently required. Traditional medicines and herbal remedies have great potential for antimicrobial drug development and there has recently been a substantial increase in interest in this field. ${ }^{8,9}$

The genus Ficus (family Moraceae) consists of approximately 850 species of trees, shrubs, vines and epiphytes. Most species are native to the tropics, although the distribution of some species extends into warm temperate zones. Whilst all species produce edible fruit, only Ficus carica L. is widely cultivated for its fruit (commonly known as figs). The fruit of all other species is also eaten as a bushfood and is only of importance to the areas in which they grow naturally. Several Ficus spp. also have medicinal uses in the treatment of a wide variety of medical disorders and conditions..$^{10}$ Ficus racemosa L. (commonly known as cluster fig, gular or Indian fig) is a large tree (Figure 1a) that is native to Australia, Indo-China and the Indian subcontinent. It produces clusters of globular edible fruit $(35 \mathrm{x} 40 \mathrm{~mm})$ that are borne on specialised shoots that protrude directly from the trunk and major branches (Figure 1b). F. racemosa has light green ovate leaves (up to $20 \mathrm{~cm}$ by $9 \mathrm{~cm}$ ) (Figure 1c).

F. racemosa has a history of usage by the first Australians to treat rheumatism, inflammation, sexually transmitted diseases and numerous infections diseases. ${ }^{11}$ In traditional Indian medicine, the leaves, bark, roots and sap have similar uses. ${ }^{10}$ The phytochemical composition of the bark of this species has been relatively well studied and a number of compounds have been identified including bergenin (Figure 1d), 
racemosic acid (Figure 1e), lupeol (Figure 1f), a-amyrin (Figure 1g), $\beta$-amyrin (Figure $1 \mathrm{~h}$ ), $\beta$-sitosterol (Figure 1i), stigmasterol (Figure $1 \mathrm{j}$ ), coumarin (Figure 1k), psoralen (Figure 1l), kaempherol (Figure 1m), gallic acid (Figure 1n), ellagic acid (Figure 1o) and rutin (Figure 1p). ${ }^{10} \mathrm{In}$ comparison, the phytochemistry of the fruit and leaves has been relatively poorly studied. This study was undertaken to screen of $F$. racemosa leaf extracts for the ability to inhibit the growth of a panel of gram-positive and gram-negative bacterial pathogens.

\section{MATERIALS AND METHODS}

\section{Plant Material \\ Collection of Plant Material and Extraction}

Ficus racemosa L. leaves were were obtained from and identified by Philip Cameron, senior botanic officer, Mt Cootha Botanical Gardens, Brisbane, Australia. The leaves were dried in a Sunbeam food dehydrator and the dried material was ground to a coarse powder. Individual $1 \mathrm{~g}$ masses of the dried plant material was extracted extensively in $50 \mathrm{ml}$ methanol (Ajax, AR grade) or deionised water for $24 \mathrm{hrs}$ at $4^{\circ} \mathrm{C}$ with gentle shaking. The extract was filtered through filter paper (Whatman No. 54) under vacuum followed by drying by rotary evaporation. The resultant pellet was dissolved in $5 \mathrm{ml}$ deionised water. The extract was passed through $0.22 \mu \mathrm{m}$ filter (Sarstedt) and stored at $4^{\circ} \mathrm{C}$.

\section{Qualitative Phytochemical Studies}

Phytochemical analysis of the F. racemosa leaf extracts for the presence of saponins, phenolic compounds, flavonoids, phytosteroids, triterpenoids, cardiac glycosides, anthraquinones, tannins and alkaloids was conducted by standard assays. ${ }^{12-14}$

\section{Antibacterial Screening Test Microorganisms}

All media was purchased from Oxoid Ltd., Australia. The reference strains of E. coli (ATCC157293), Klebsiella pneumoniae (ATCC31488), Proteus mirabilis (ATCC21721) and Streptococcus pyogenes (ATCC19615) were purchased from American Tissue Culture Collection (ATCC), USA. Clinical isolate microbial strains of Aeromonas hydrophilia, Alcaligenes feacalis, Bacillus cereus, Citrobacter freundii, Pseudomonas fluorescens, Salmonella newport, Serratia marcescens, Shigella sonneii, Staphylococcus aureus and Staphylococcus epidermidis strains were obtained from Ms Michelle Mendell and Ms Jane Gifkins, Griffith University. All stock cultures were subcultured and maintained in nutrient broth at $4^{\circ} \mathrm{C}$.

\section{Evaluation of Antimicrobial Activity}

Antimicrobial activity of the F. racemosa leaf extracts was determined using a modified disc diffusion assay. ${ }^{15-17}$ Briefly, $100 \mu \mathrm{L}$ of the each bacterial suspension in log phase was spread onto individual nutrient agar plates and the extracts were tested for antibacterial activity using $6 \mathrm{~mm}$ sterilised filter paper discs. The discs were each infused with $10 \mu \mathrm{L}$ of the individual plant extract, allowed to dry and placed onto the inoculated plates. The plates were allowed to stand at $4^{\circ} \mathrm{C}$ for $2 \mathrm{~h}$ before incubation at $37^{\circ} \mathrm{C}$ for $24 \mathrm{~h}$. The diameters of the zones of inhibition (ZOIs) were measured to the closest whole millimetre. Each assay was performed three times in triplicate $(n=9)$. Mean values $( \pm$ SEM) are reported in this study. Standard discs of ampicillin $(10 \mu \mathrm{g})$ and chloramphenicol $(10 \mu \mathrm{g})$ were obtained from Oxoid, Australia and were used as positive controls to compare antibacterial activity. Filter discs infused with $10 \mu \mathrm{L}$ of distilled water were used as a negative control.

\section{Artemia franciscana Nauplii Toxicity Screening}

Toxicity was tested using an adapted Artemia franciscana nauplii lethality assay. ${ }^{18-20}$ Briefly, $A$. franciscana nauplii were incubated in the pres- ence of the extracts, reference toxin $(1 \mathrm{mg} / \mathrm{mL}$ potassium dichromate) or artificial seawater (negative control) at $25 \pm 1^{\circ} \mathrm{C}$ under artificial light. All treatments were performed three times in triplicate $(n=9)$. The number of dead were counted in each well at $24 \mathrm{~h}$. At the completion of the $24 \mathrm{~h}$ exposure period, the remaining live nauplii were sacrificed and the total number of nauplii in each well were counted and used to calculate the \% mortality per well. $\mathrm{LC}_{50}$ values were calculated for each treatment using probit analysis.

\section{Statistical analysis}

Data are expressed as the mean \pm SEM of three independent experiments with internal triplicates $(n=9)$. One-way ANOVA was used to calculate statistical significance between control and treated groups, with a $P$ value $<0.01$ considered to be statistically significant.

\section{RESULTS}

\section{Liquid extraction yields and qualitative phytochemical screening}

Extraction of $1 \mathrm{~g}$ of dried and powdered F. racemosa leaves with methanol and water yielded 338 and $250 \mathrm{mg}$ of extracted material respectively (Table 1). The extracts were resuspended in $10 \mathrm{~mL}$ of deionised water (containing 1\% DMSO), resulting in an extract concentration shown in Table 1. Qualitative phytochemical studies showed that both extracts had similar phytochemical profiles. Both contained moderate to high levels of phenolic compounds, flavonoids and tannins. Lower levels of saponins, phytosterols and alkaloids were also detected. Cardiac glycosides, triterpenoids and anthraquinones were generally absent or below the detection thresholds for these assays.

\section{Antibacterial activity}

To determine the growth inhibitory activity of the F. racemosa leaf extracts, aliquots $(10 \mu \mathrm{L})$ of each extract were screened in the disc diffusion assay. The F. racemosa leaf extracts were ineffective at inhib-

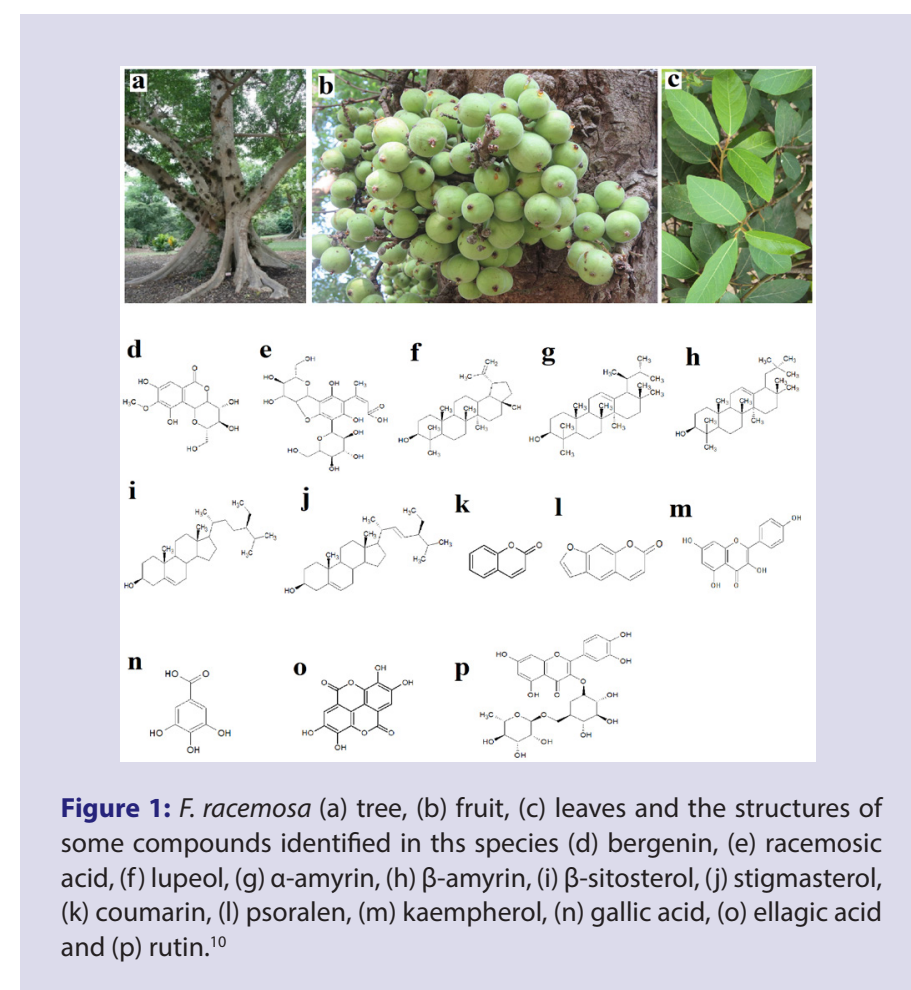


Table 1: The mass of dried extracted material, the concentration after resuspension in deionised water and qualitative phytochemical screenings of the $F$. racemosa leaf extracts.

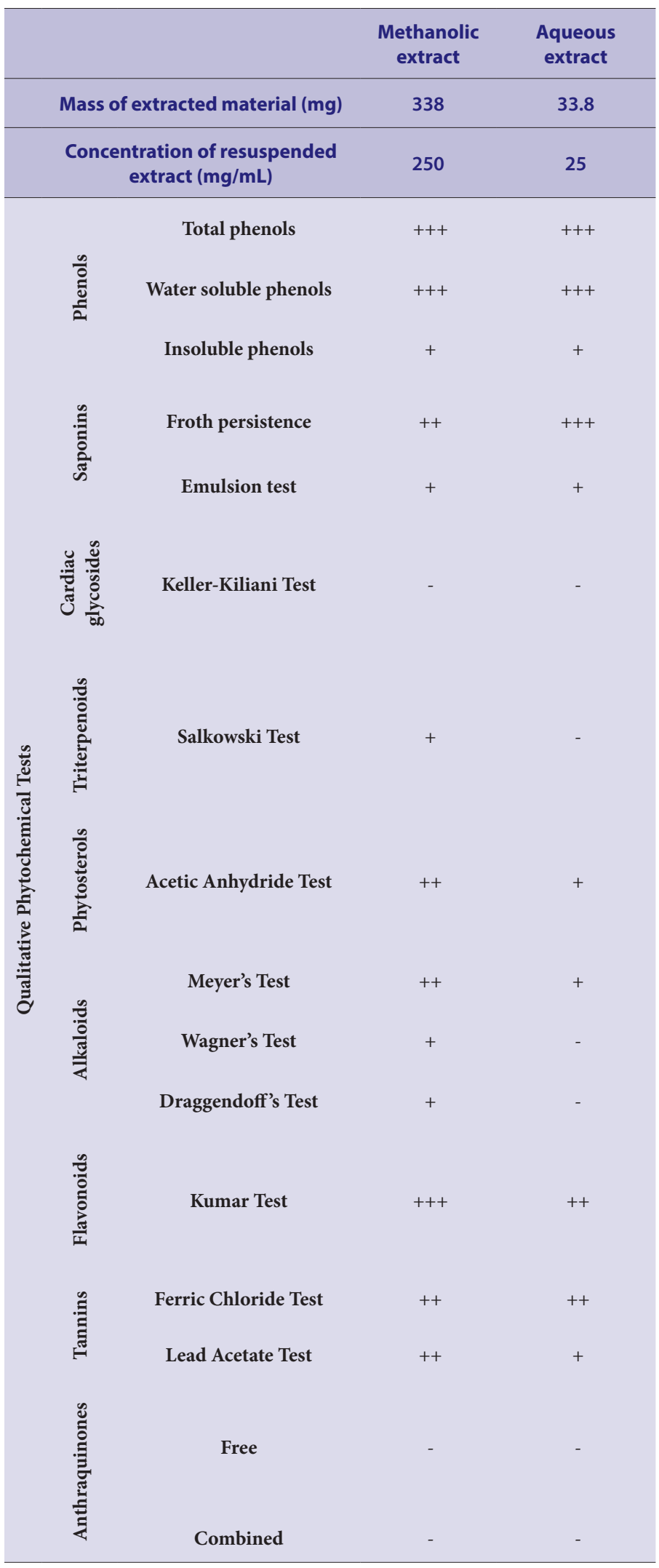

+++ indicates a large response; ++ indicates a moderate response; + indicates a minor response; - indicates no response in the assay.

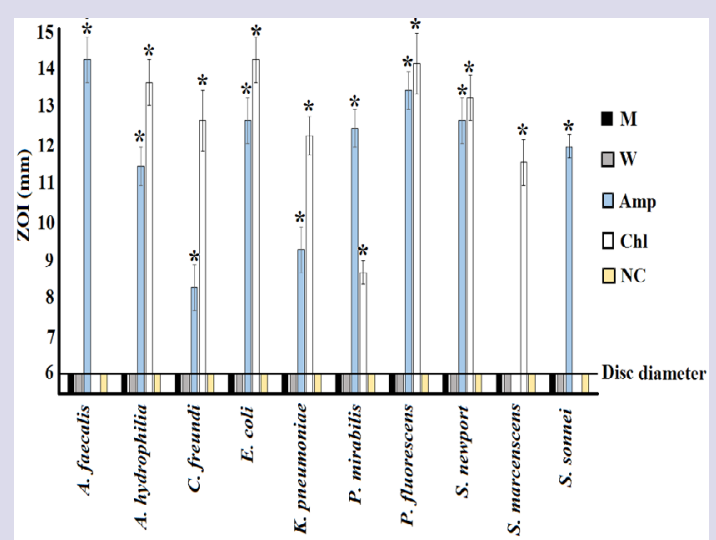

Figure 2: Growth inhibitory activity of $F$. racemosa leaf extracts and reference antibiotics against gram-negative bacterial species measured as ZOls $(\mathrm{mm}) \pm$ SEM. Ampicillin (Amp) and chloramphenicol (Chl) standard discs $(10 \mu \mathrm{g})$ were used as positive controls. $\mathrm{M}=$ methanolic extract; $\mathrm{W}=$ aqueous extract; $\mathrm{NC}=$ negative control. All assays were completed three times, each with internal triplicates $(n=9)$ and the results are expressed as mean zones of inhibition $(\mathrm{mm}) \pm$ SEM.

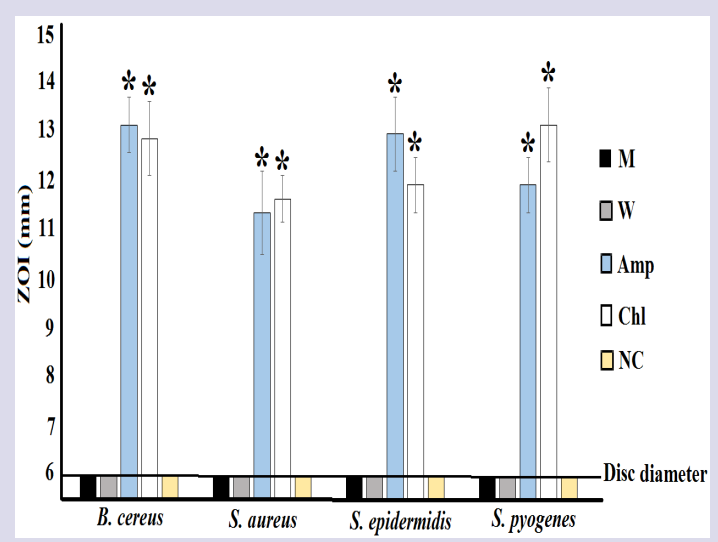

Figure 3: Growth inhibitory activity of $F$. racemosa leaf extracts and reference antibiotics against gram-positive bacterial species measured as ZOls $(\mathrm{mm}) \pm$ SEM. Ampicillin (Amp) and chloramphenicol (Chl) standard discs $(10 \mu \mathrm{g})$ were used as positive controls. $\mathrm{M}=$ methanolic extract; $\mathrm{W}=$ aqueous extract; $\mathrm{NC}=$ negative control. All assays were completed three times, each with internal triplicates $(n=9)$ and the results are expressed as mean zones of inhibition $(\mathrm{mm}) \pm \mathrm{SEM}$.

iting the growth of all gram-negative (Figure 2) and gram positive (Figure 3) bacterial species tested. In contrast, both positive control antibiotics (ampicillin and chloramphenicol) were effective growth inhibitors, with ZOI's of up to $14.3 \mathrm{~mm}$ (chloramphenicol against $E$. coli). We were therefore unable to determe the MIC values for any extract as they were completely ineffective at all concentrations tested.

\section{Quantification of Toxicity}

The toxicity of the F. racemosa leaf extracts was initially tested at $1 \mathrm{mg} /$ $\mathrm{mL}$ in the A. franciscana nauplii bioassay (Figure 4). All extracts induced $100 \%$ mortality at $24 \mathrm{~h}$ and were therefore deemed to be toxic. Extracts with $24 \mathrm{~h} \mathrm{LC}_{50}$ values $>1000 \mu \mathrm{g} / \mathrm{mL}$ have previously been defined as non-toxic. ${ }^{20}$ The potassium dichromate positive control also induced 


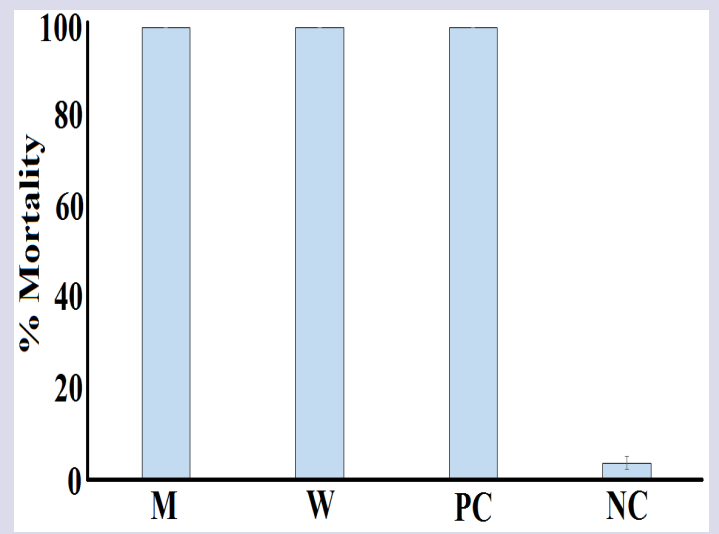

Figure 4: The lethality of the $F$. racemosa leaf extracts $(1000 \mu \mathrm{g} / \mathrm{mL})$, potassium dichromate control $(1000 \mu \mathrm{g} / \mathrm{mL}$ ) and seawater (negative control) following 24 , hrs of exposure. All bioassays were performed three times in triplicate $(n=9)$ and are expressed as mean \pm SEM. * indicates results that are significantly different to the untreated (seawater) control at the equivalent exposure time $(P<0.01)$.

substantial mortality within 4 h (results not shown), with $100 \%$ mortality induction seen by $24 \mathrm{~h}$, whilst the seawater (negative control) induced $<5 \%$ mortality at $24 \mathrm{hrs}$.

\section{DISCUSSION}

Due to recent increases in bacterial resistance to many antibiotics, the development of new antibiotic chemotherapies is a high priority for medical science. ${ }^{6,7}$ A parallel decrease in the discovery of new antibiotic medicines by conventional strategies has increased interest in re-evaluating medicinal plants for new antibiotic chemotherapies. ${ }^{21}$ F. racemosa was used by the first Australians to treat a number of diseases, ${ }^{11}$ some of which are caused by bacterial pathogens. Similarly, traditional Indian healers also used the bark of this species to treat numerous pathogens. ${ }^{10}$ Interestingly, the F. racemosa extracts were completely inactive against all gram-positive and gram-negative bacteria tested. It is noteworthy that a single assay technique was used to screen for antibacterial activity in this study. We chose to use the disc diffusion assay as it is a rapid methodology and it has previously been widely utilised in other studies. Therefore, comparisons between studies are relatively simple. However, as the disc diffusion method is reliant on the diffusion of a molecule through the aqueous environment of an agar gel, this assay may be affected by the solubility of the extract compounds in the aqueous environment. Polar compounds that are highly soluble in water would be expected to diffuse easily in the gel, whereas less soluble compounds would not diffuse as readily and thus be concentrated around the disc. For this reason, whilst this is a handy assay for screening aqueous extracts, this technique may not be ideal for nonpolar compounds (e.g. when screening essential oil and their components). Liquid dilution studies may have been better suited to screen the F. racemosa for activity and future studies will use these techniques to re-examine the extracts for antibacterial activity.

Diffusion of molecules within aa agar gel is also affected by the size of the molecules. The movement of large, complex phytochemicals (eg. complex tannins) through agar gels by diffusion would also be retarded and may provide a false idea of the efficacy of an extract. As many tannins have well described antibiotic properties, screening for growth inhibition using agar diffusion techniques may give a distorted view of its inhibitory potential. The findings reported here indicate that the extracts examined were toxic $\left(24 \mathrm{hr} \mathrm{LC}_{50}<1000 \mu \mathrm{g} / \mathrm{mL}\right)$ in the Artemia nauplii bioassay. Whilst toxicity was assessed in this study with the test organism A. franciscana, toxicity towards A. franciscana has previously been shown to correlate well with toxicity towards human cells for many toxins. ${ }^{20}$ However, further studies are required to determine whether this is also true for the F. racemosa leaf extracts examined in these studies.

\section{CONCLUSION}

Methanolic and aqueous $F$. racemosa leaf extracts displayed no antibacterial activity in the disc diffusion assay against a panel of human pathogenic bacteria, despite their traditiojnal medicinal uses and their close taxonomic relationship with Ficus spp. with known antibacterial properties. The extracts were toxic towards Artemia nauplii.

\section{ACKNOWLEDGEMENT}

The authors are grateful to Michelle Mendell and Jane Gifkins of Griffith University for providing the clinical bacterial strains used in this study. Financial support for this work was provided by the Environmental Futures Research Institute and the School of Natural Sciences, Griffith University, Australia.

\section{CONFLICT OF INTEREST}

The authors report no conflicts of interest.

\section{ABBREVIATIONS}

DMSO: Dimethyl sulfoxide; $\mathbf{L C}_{50}$ : The concentration required to achieve 50 \% mortality; MIC: Minimum Inhibitory Concentration; ZOI: Zone of inhibition.

\section{REFERENCES}

1. Kamboj VP. Herbal medicine. Curr Sci. 2000;78:35-9.

2. Hostettmann K, Hamburger M. Search for new lead compounds of natural origin. In Perspectives in Medical Chemistry. Verlag Helvitica Acta, Basel. 1993.

3. Newman DJ, Cragg GM, Snader KM. The influence of natural products on drug discovery. Nat Prod Rep. 2000;17(3):215-34.

4. Walsh G. Biopharmaceuticals: Biochemistry and Biotechnology. $3^{\text {rd }}$ ed. Wiley, Chinchester. 2003.

5. Gilani AH, Atta-ur-Rahman. Trends in ethnopharmacology. J Ethnopharmacol. 2005; 100(1-2):43-9.

6. Cheesman MJ, llanko A, Blonk B, Cock IE. Developing new antimicrobial therapies: Are synergistic combinations of plant extracts/compounds with conventional antibiotics the solution?. Pharmacognosy Reviews. 2017;11(22):5772. DOI: 10.4103/phrev.phrev_21_17

7. WHO. Antimicrobial Resistance. World Health Organization. 2016. Available from: http://www.who.int/mediacentre/factsheets/fs194/en/. [Cited on 2017 May 10].

8. Sirdaarta J, Matthews B, Cock IE. Kakadu plum fruit extracts inhibit the growth of the bacterial triggers of rheumatoid arthritis: Identification of stilbene and tannin components. Journal of Functional Food. 2015;17:610-20. DOI: 10.1016/j. jff.2015.06.019

9. Ilanko A, Cock IE. The interactive antimicrobial activity of contentional antibiotics and Petalostigma spp. Extracts against bacterial triggers of some autoimmune inflammatory diseases. Pharmacognosy Journal. 2019;11(2):292-309.

10. Ahmed F, Urooj A. Traditional; uses, medicinal properties and phytopharmacology of Ficus racemosa: A review. Pharmaceutical Biology. 2010;48(6):672-81.

11. Lassak EV, McCarthy TM. Australian medicinal plants. A complete guide tom identification and usage. Reed New Holland Publishers. Sydney Australia. 2011

12. Hart C, Ilanko P, Sirdaarta J, et al. Tasmannia stipitata as a functional food/ natural preservative: Antimicrobial cctivity and toxicity. Pharmacognosy Communications. 2014;4(4):33-47. DOI: 10.5530/pc.2014.4.4

13. Winnett $V$, Sirdaarta J, White $A$, et al. Inhibition of Klebsiella pneumonia growth by selected Australian plants: Natural approaches for the prevention and management of ankylosing spondylitis. Inflammopharmacology. 2017;25(2):223-35. DOI: 10.1007/s10787-017-0328-1

14. Wright MH, Matthews B, Arnold MSJ, et al. The prevention of fish spoilage by high antioxidant Australian culinary plants: Shewanella putrefaciens growth inhibition. International Journal of Food Science and Technology. 2016;51(3):801- 
13. DOI: $10.1111 /$ ijfs. 13026

15. Mpala L, Chikowe G, Cock IE. No evidence of antiseptic properties and low toxicity of selected Aloe species. Journal of Pharmaceutical Negative Results. 2010;1(1):10-6.

16. Lee CJ, Wright MH, Arnold MSJ, et al. Inhibition of Streptococcus pyogenes growth by native Australian plants: New approaches towards the management of impetigo, pharyngitis and rheumatic heart disease. Pharmacognosy Communications. 2016;6(3):164-73.

17. Wright $\mathrm{MH}$, Arnold MSJ, Lee CJ, et al. Qualitative phytochemical analysis and antibacterial activity evaluation of Indian Terminalia spp. Against the pharyngitis causing pathogen Streptococcus pyogenes. Pharmacognosy Communications. 2016;6(2):85-92
18. Cock IE, Winnett V, Sirdaarta J, et al. The potential of selected Australian medicinal plants with anti-Proteus activity for the treatment and prevention of rheumatoid arthritis. Pharmacognosy Magazine. 2015;11(Suppl 1):S190-208.

19. Hart C, Cock IE. An examination of the antimicrobial and anticancer properties of Garcinia cambogia fruit pericarp extracts. BEMS Reports. 2016;2(1):23-6.

20. Cock IE, Ruebhart DR. Comparison of the brine shrimp nauplii bioassay and the ToxScreen-II test for the detection of toxicity associated with Aloe vera (Aloe barbadensis Miller) leaf extract. Pharmacognosy Research. 2009;1(2):98-101.

21. Aiyegoro OA, Okoh Al. Use of bioactive plant products in combination with standard antibiotics: Implications in antimicrobial chemotherapy. Journal of Medicinal Plants Research. 2009;3(13):1147-52.

\section{PICTORIAL ABSTRACT}

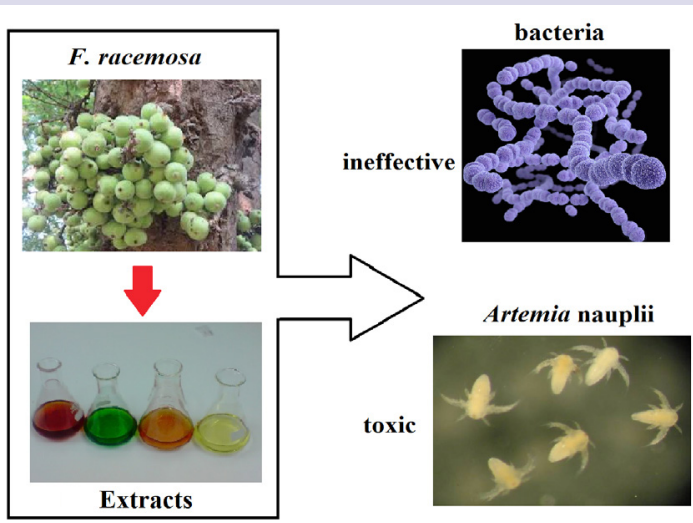

\section{SUMMARY}

- F. racemosa leaf extracts were screened for the ability to block the growth of a panel of human bacterial pathogens.

- No inhibitory activity was evident against any of the bacterial species tested

- $\quad$ Toxicity of the F. racemosa extracts was determined using the Artemia nauplii toxicity bioassay.

- $\quad$ Both the methanolic and aqueous extracts were nontoxic.

\section{ABOUT AUTHORS}

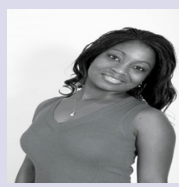

Ms Lindiwe Mpala, completed at BSc at Griffith University in life sciences. Following graduation, she undertook a research project in Dr lan Cock's laboratory in the School of Natural Sciences at Griffith University. The project examined the growth inhibitory properties of a variety of Australian native plants against an extensive panel of bacterial pathogens.

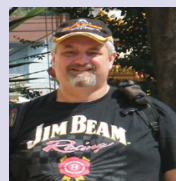

Dr. Ian Cock leads a research team in the Environmental Futures Research Institute and the School of Natural Sciences at Griffith University, Australia. His research involves bioactivity and phytochemical studies into a variety of plant species of both Australian and international origin, including Aloe vera, South Asian and South American tropical fruits, as well as Australia plants including Scaevola spinescens, Pittosporum phylliraeoides, Terminalia ferdinandiana (Kakadu plum), Australian Acacias, Syzygiums, Petalostigmas and Xanthorrhoea johnsonii (grass trees). This range of projects has resulted in nearly 200 publications in a variety of peer reviewed journals.

Ms. Getmore Chikowe completed at BSc at Griffith University in life sciences. Following graduation, she undertook a research project in Dr lan Cock's laboratory in the School of Natural Sciences at Griffith University. The project examined the growth inhibitory properties of a variety of Australian native plants against an extensive panel of bacterial pathogens. 